\title{
Laparoscopic Assisted Ultrasound Guided Percutaneous Nephrolithotomy (PCNL) in Ectopic Pelvic Kidney
}

\section{Mohammad Hadi $\operatorname{Radfar}^{1}{ }^{(\mathbb{D})}$, Alireza Golshan $^{2}{ }^{(\mathbb{D})}$, Sepehr Hamedanchi $^{3^{(\mathbb{D})}}$, Hamid Pakmanesh"}

1. Assistant Professor, Department of Urology, Shahid Labbafinejad Center, Shahid Beheshti University of Medical Sciences, Tehran, Iran

2. Assistant Professor, Department of Urology, Department of Surgery, School of Medicine, Razavi Khorasan University of Medical Sciences, Mashhad, Iran

3. Assistant Professor, Department of Urology, Urmia University of Medical Sciences, Urmia, Iran

4. Assistant Professor, Department of Urology, Kerman University of Medical Sciences, Kerman, Iran

\section{Article Information}

\begin{tabular}{ll}
\multicolumn{2}{c}{ Article History } \\
Received: & $2019 / 06 / 22$ \\
Accepted: & $2018 / 06 / 27$ \\
Available Online: & $2019 / 09 / 16$
\end{tabular}

JUR 2019; 3(1):28-32

DOI: 10.30699/jru.3.1.28

Use your device to scan and read the article online

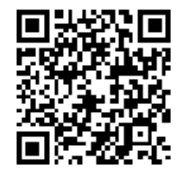

Corresponding Author

Hamid Pakmanesh

Assistant Professor, Department of Urology, Kerman University of Medical Sciences, Kerman, Iran

Email:

h_pakmanesh@kmu.ac.ir

\section{Abstract}

We report a patient with pain, abdominal palpable mass and a history of previous open renal stone surgery. Imaging studies showed a right pelvic kidney with multiple calyceal stones. We aim to describe the successful management through laparoscopic assisted percutaneous nephrolithotomy with ultrasonography (PCNL) in ectopic pelvic kidney, stressing that this method is a minimally invasive therapeutic option in such cases; especially ultrasound was used for locating the stones and getting access to the collecting system instead of the fluoroscopy.

Keywords: Kidney, Percutaneous nephrolithotomy, Stone, Laparoscopy

How to cite this article:

Radfar M H, Golshan A, Hamedanchi S, Pakmanesh H. Laparoscopic Assisted Ultrasound Guided Percutaneous Nephrolithotomy (PCNL) in Ectopic Pelvic Kidney. J Res Urol. 2019; 3 (1): 28-32 
جراحى سنَ كليه از طريق يوست (PCNL) با هدايت سونوگر افى به كمك لاياروسكويى در

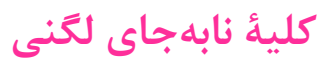

(iD)

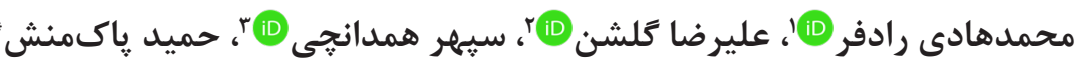

1. استاديار، تروه اورولوزى، مركز شهيد لبافىنزاد، دانشعاه علوم يزشكى شهيد بهشتى، تهران، ايران

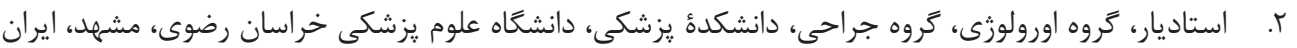

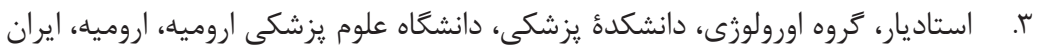

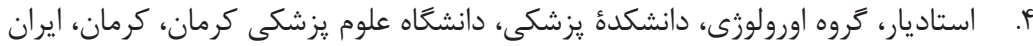

\begin{tabular}{|c|c|}
\hline جكيده & اطلاعات مقاله \\
\hline & تاريخجة مقاله \\
\hline ما بيمارى را كزارش مى كنيم كه با درد و تودئ قابل لمس شكمى مراجعه كرد و در بررسىهاى راديولوزيك & $|r q N| \cdot 4 / \cdot 1$ \\
\hline 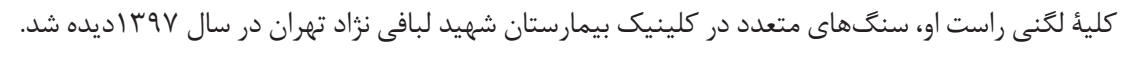 & $\mid r q V / \cdot \varphi / \cdot \varphi$ \\
\hline 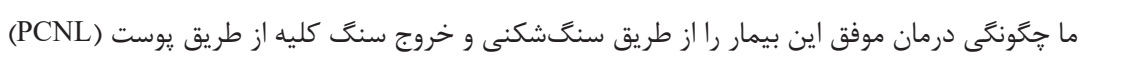 & 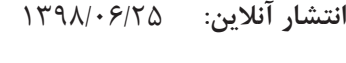 \\
\hline به كمك لإياراسكويى و البته تحت هدايت همزمان سونوكرافى شرح مى دهيم. با تأكيد بر كمتهاجمىبودن اين & JUR 2019; 3(1):28-32 \\
\hline روش، به خصوص به جاى استفاده از فلوروسكويى، از سونوكرافى براى ورود مطمئن و بدون أسيب به داخل & \\
\hline 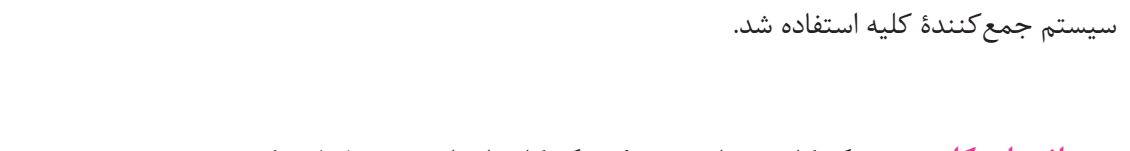 & كد زير ران با موبايل خود اين مقاله، \\
\hline وازههاى كليدى: سنگ كليه، جراحى بستة سنك كليه از راه بوست، لإياروسكويى & 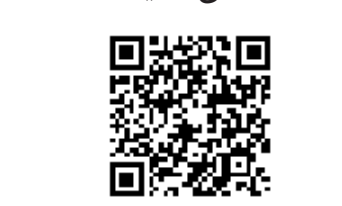 \\
\hline
\end{tabular}

نويسندة مسئول: حميد پاكمنش، استاديار اورولوزى، دانشكدة يزشكى، دانشكاه علوم يزشكى كرمان، كرمان، ايران h_pakmanesh@kmu.ac.ir : ايميل 


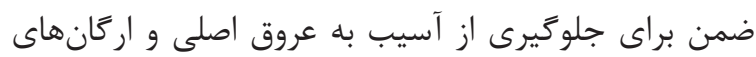

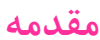

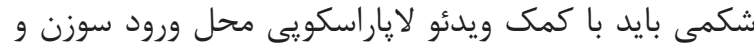

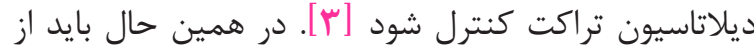

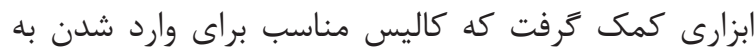

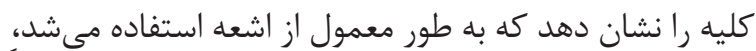

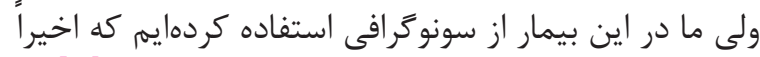

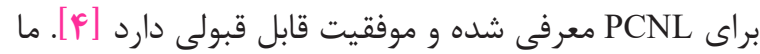

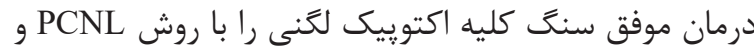

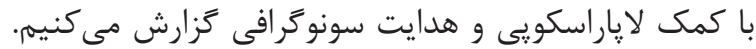

\section{كَزارش مورد}

مردى هأساله با شكايت درد و تودة قابل لمس شكمى شكى

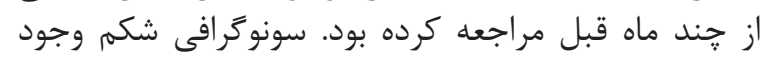
كليئ نابهجاى راست لكنى بلى به همراه

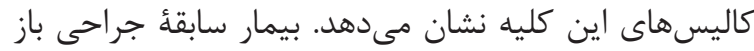

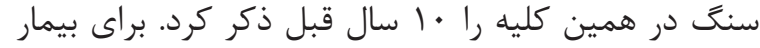

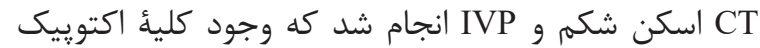

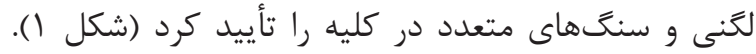

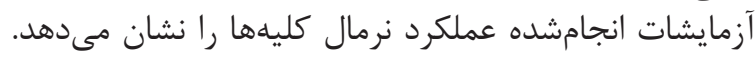
همجنين آزمايش كشت ادرار عملرد نرمال كليشى بود.

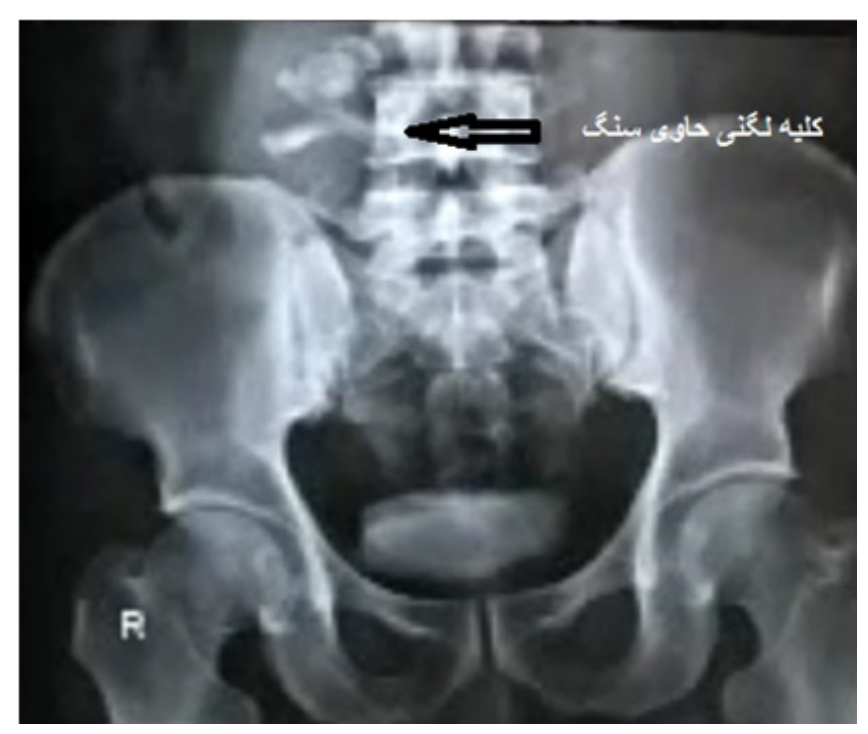

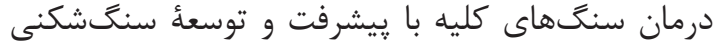

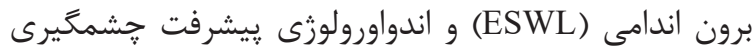

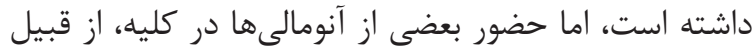

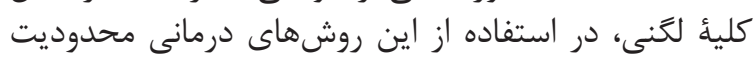

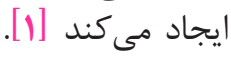

كليهٔ لكنى شايعترين نوع كليههاى اكتوِيك است. بروز

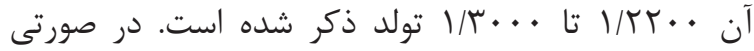

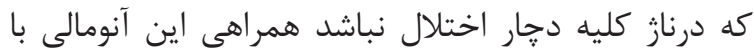

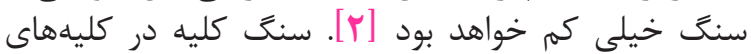

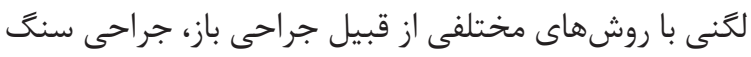

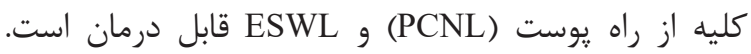

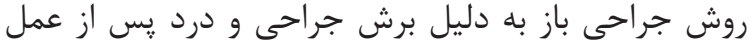

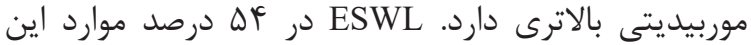

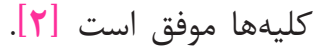

PCNL در اين كليهها انجامشدنى است، ولى روش انجام انجام

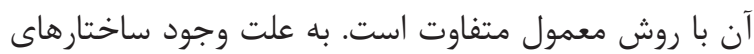

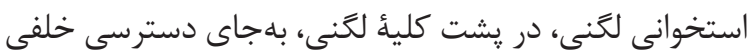
به كليه بايد از قدام شكم به كليه دليه دسترسى بيد بيدا كرد و در درى

شكل ا. بيلوكَرافى ترشحى كليةُ راست در لكَن.

يريتوئن خلفى از روى كليئ لكنى كنار زده و به به همين ترتيب

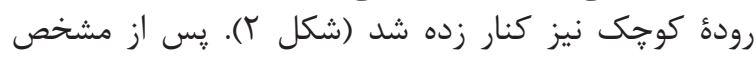

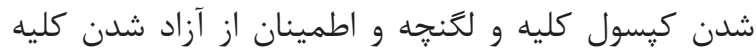

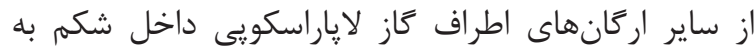

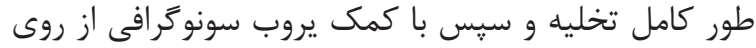

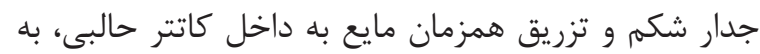

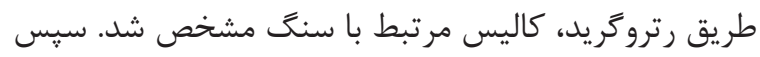

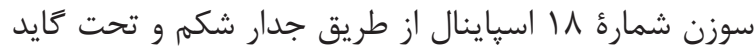

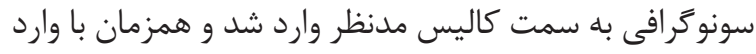

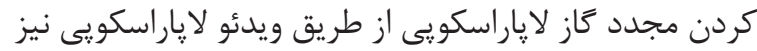

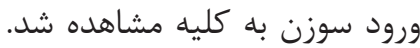

يس از بيهوشى كامل بيمار در يوزيشن ليتوتومى تحت

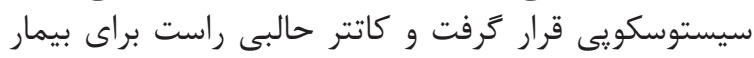

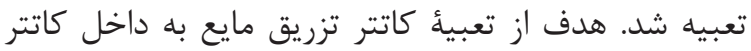

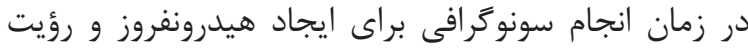

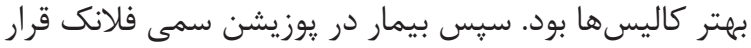

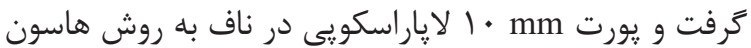
باز قرار ترفت. سيس كاز CO2 با فشار

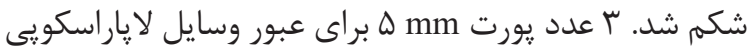

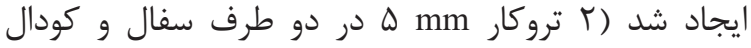

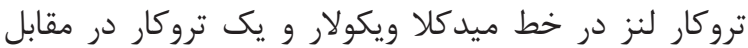

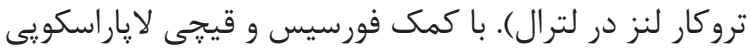




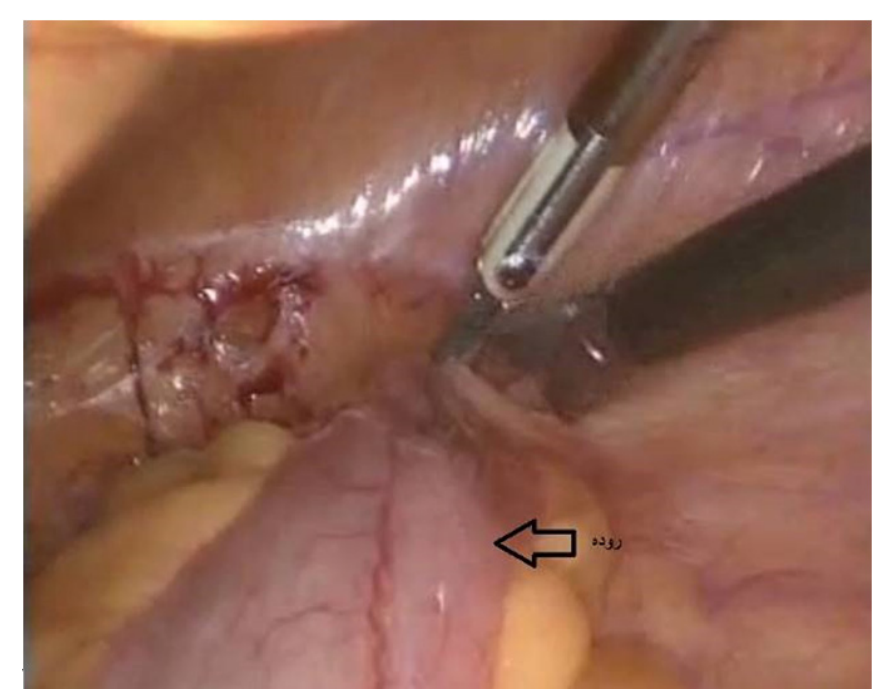

شكل r. كنار زدن روده از روى كليئ لكنى به كمك لاياروسكويى.

انجام PCNL در كليههاى لكنى به علت شكل غيرطبيعى

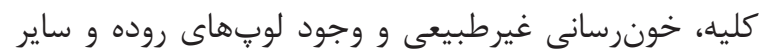

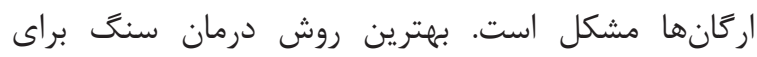

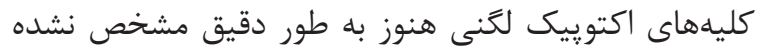

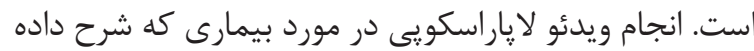

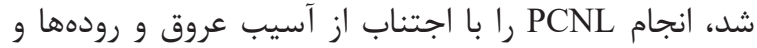
ساير اركانهاى اطراف امكانيذير مى كند.

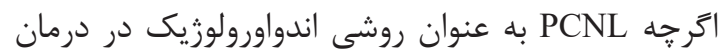

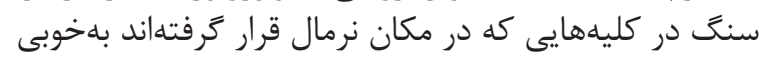

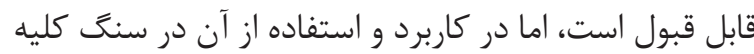

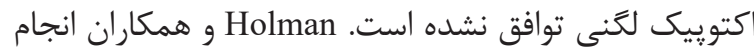

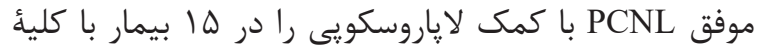

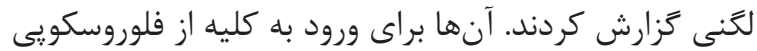

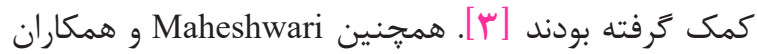

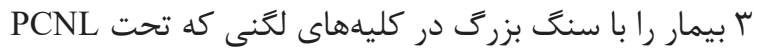

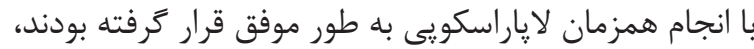

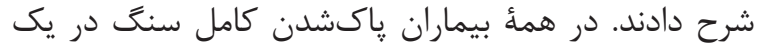

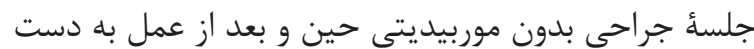

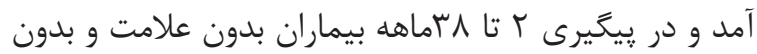

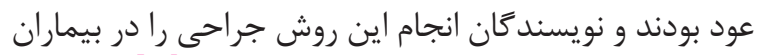

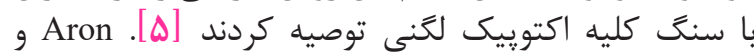

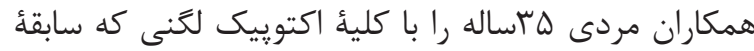

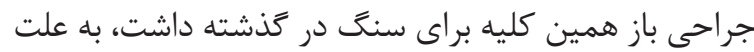

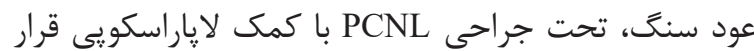

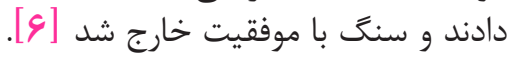

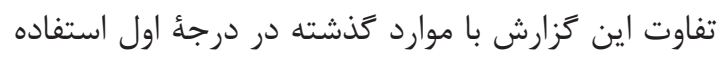

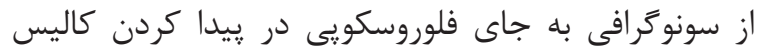

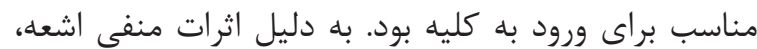

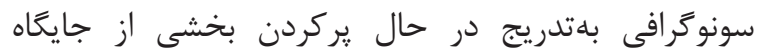

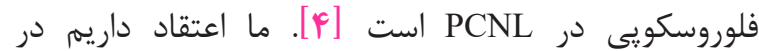

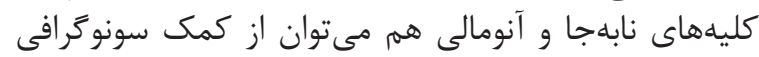

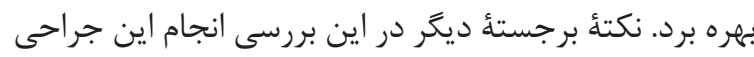

بعد از آسبيرهشدن ادرار، از طريق سوزن، كايد واير وارد و

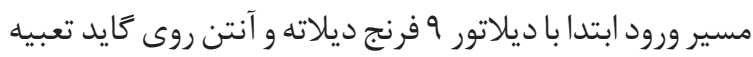

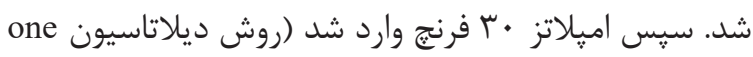

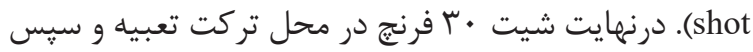

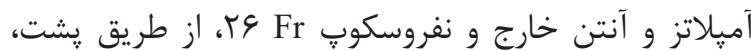

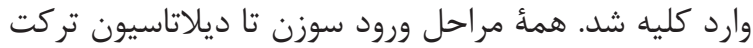

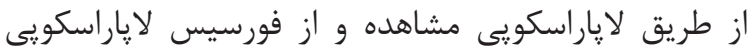

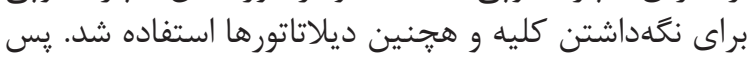

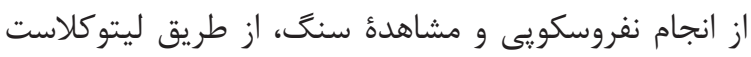

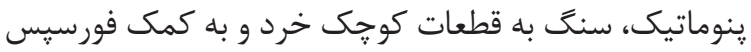

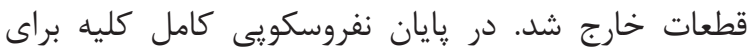

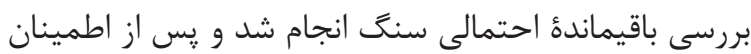

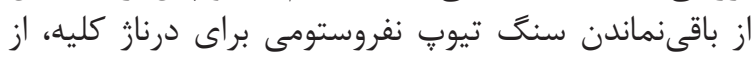

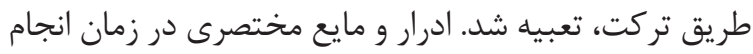

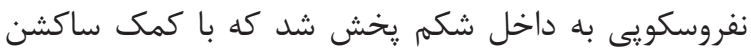

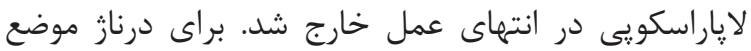

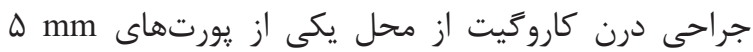

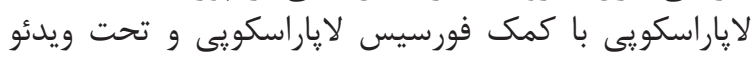

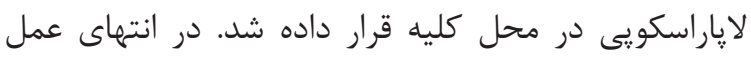

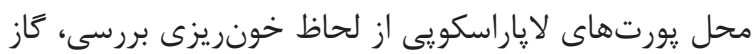

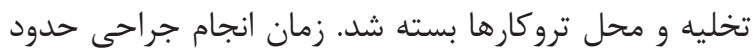

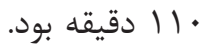

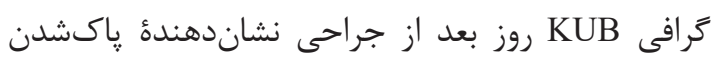

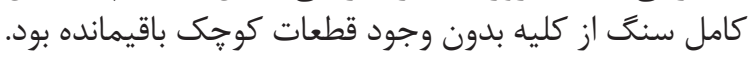

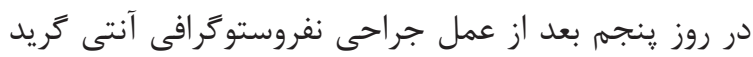

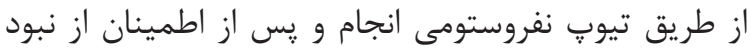

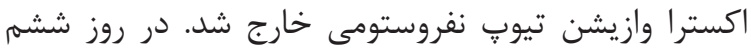

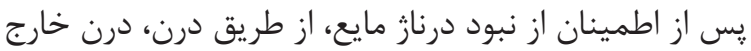

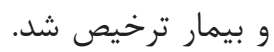

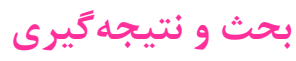

كليئ للَنى شايعترين نوع از انواع كليههاى اكتوييك است.

r) 


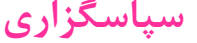

$$
\begin{aligned}
& \text { ازتمامىهمكارانى كه به ما در انجام اين يزوهش يارى } \\
& \text { رساندند، تشكر و قدردانى مىشود. } \\
& \text { تعارض در منافع } \\
& \text { بين نويسندگان هيجگَّنه تعارضى در منافع وجود ندارد. }
\end{aligned}
$$

\section{References}

1. Matlaga BR, Assimos DG. Changing indications of open stone surgery. Urology. 2002 Apr 1;59(4):490-3.

2. Paterson RF, Lifshitz DA, Kuo RL, Siqueira Jr TM, Lingeman JE. Shock wave lithotripsy monotherapy for renal calculi. Int Braz $\mathrm{J}$ Urol. 2002 Jul;28(4):291-301.

3. HOLMAN E, Tóth C. Laparoscopically assisted percutaneous transperitoneal nephrolithotomy in pelvic dystopic kidneys: experience in 15 successful cases. Journal of Laparoendoscopic \& Advanced Surgical Techniques. 1998 Dec;8(6):431-5.

4. Nouralizadeh A, Pakmanesh H, Basiri A, Aayanifard M, Soltani MH, Tabibi A, Shar-

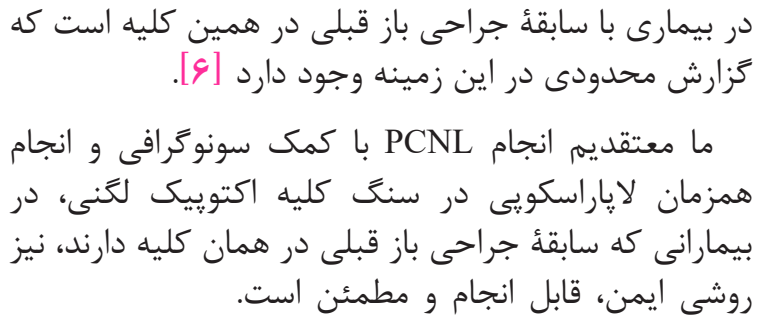

ifiaghdas F, Ziaee SA, Shakhssalim N, Valipour R, Narouie B. Solo sonographically guided PCNL under spinal anesthesia: defining predictors of success. Scientifica. 2016;2016.

5. Maheshwari PN, Bhandarkar DS, Andankar MG, Shah RS. Laparoscopically guided transperitoneal percutaneous nephrolithotomy for calculi in pelvic ectopic kidneys. Surgical Endoscopy And Other Interventional Techniques. 2004 Jul 1;18(7):1151-.

6. Aron M, Gupta NP, Goel R, Ansari MS. Laparoscopy-assisted percutaneous nephrolithotomy (PCNL) in previously operated ectopic pelvic kidney. Surgical Laparoscopy Endoscopy \& Percutaneous Techniques. 2005 Feb 1;15(1):41-3. 